\title{
Strengths and Microstructure of SUS316L Fabricated by Selective Laser Melting ${ }^{* 1}$
}

\author{
Kazuki Akino $^{* 2}$ and Koji Kakehi \\ Department of Mechanical Engineering, Graduate School of Science and Engineering, Tokyo Metropolitan University, \\ Tokyo 192-0397, Japan
}

The additive manufacturing (AM) process, which can produce highly complex components, has been getting significant attention in both industry and academic research. Ti-based alloys, Ni-based superalloys, and Co-Cr-based alloys have been widely investigated. However, as Ni-based superalloys have precipitated phases such as the $\gamma^{\prime}$ and $\gamma^{\prime \prime}$ phases, and Ti-based alloys and Co-Cr-based alloys are multiphase alloys which have phase transformation, it is difficult to clarify the factors in the AM process that influence the strength of these alloys. In this study, SUS316L stainless steel, which is a single-phase solid-solution alloy and does not have precipitated phases, was used to investigate the effect of specific factors in the AM process on anisotropy or mechanical properties, and the strengthening mechanism in the AM process in comparison with SUS316L plastic-forming (PF) material. The AM SUS316L was fabricated by selective laser melting using an ytterbium fiber laser from fine metallic powder. We found that the coarse columnar grains grew up along the built direction and the dislocation cell structures which were induced during the AM process into the AM material. During the solution heat treatment, dislocation recovery was observed. The AM specimens showed higher tensile and creep strength compared with the conventional material (the PF material) because of the high dislocation density. The ductility of the AM specimens was lower than that of the conventional material because of defects caused by a lack of fusion at the molten pool boundaries. Furthermore, the specimens whose loading direction corresponds to the built direction showed lower strength and elongation than the specimens whose loading direction was perpendicular to the built direction due to the oriented defects. [doi:10.2320/matertrans.M2017163]

(Received October 5, 2017; Accepted December 8, 2017; Published January 26, 2018)

Keywords: additive manufacturing, austenite stainless steel, solid-solution alloy, built direction, molten pool boundary

\section{Introduction}

$3 \mathrm{D}$ printing of metal that is known as near net shape manufacturing and has a large degree of design flexibility that is for the purpose of weight saving has become a focus of research recently ${ }^{1)}$. Ti-based alloys, Ni-based superalloys, and Co-Cr-based alloys built up by the additive manufacturing (AM) process have been widely investigated. However, as Ti-based alloys ${ }^{2)}$ and Co-Cr-based alloys ${ }^{3)}$ undergo phase transformation during the AM process, and Ni-based superalloys ${ }^{4,5)}$ precipitate the $\gamma^{\prime}$ and $\gamma^{\prime \prime}$ phases in the $\gamma$ matrix, it is difficult to clarify the specific factors of the AM process that contribute to the anisotropy or mechanical properties of the product.

In this study, SUS316L stainless steel, which is a singlephase solid-solution alloy and does not have precipitated phases, was used to investigate the specific factors of the $\mathrm{AM}$ process that contribute to the anisotropy or mechanical properties due to successional Molten Pool Boundaries (MPBs) and defects caused by AM process and the strengthening mechanism in comparison with a plastic-forming (PF) material.

\section{Materials and Experimental Procedures}

An AM SUS316L block with the dimensions of $50 \times 50 \times$

\footnotetext{
${ }^{* 1}$ This Paper was Originally Published in Japanese in J. Japan Inst. Met. Mater. 80 (2016) 772-777. In order to more precisely explain the background, the experimental procedures, and the results, some parts of the contents were revised. The revised contents were enumerated bellow. The sentence of "abstract", "introduction", "materials and experimental procedures", "result", "discussion", and "conclusion", Fig. 4, and the title of Table 1, Table 2, Fig. 1, Fig. 3, Fig. 4, Fig. 5, Fig. 9, and Fig. 10 were slightly modified. Fig. 9(b) was exchanged to another TEM image.

${ }^{* 2}$ Graduate Student, Tokyo Metropolitan University
}

$50 \mathrm{~mm}^{3}$ (Fig. 1) was fabricated by an SLM 280 (SLM Solutions, GmbH, Germany), which consists of an ytterbium fiber laser, from fine metallic powder fabricated by LPW Technology Ltd. The ytterbium fiber laser scanned in a single direction over $7 \mathrm{~mm}^{2}$ areas; the scanning directions of adjacent areas were perpendicular to each other. The chamber of the SLM 280 was evacuated, then filled in with argon or nitrogen gas to form an oxygen-free atmosphere. The comparative material was a conventional hot working PF rod. Table 1 shows the chemical compositions of the primitive powder and PF material. The AM block was cut in $3.1 \mathrm{~mm}$ thick slices perpendicularly (i.e., the cutting plane was perpendicular to the built plane). Subsequently the tensile specimens evaluated in this study were fabricated by cutting with their loading axes parallel to the built direction (0-deg specimens), and their loading axes were perpendicular to the built direction (90-deg specimens). Dumbbellshaped specimens of $2.8 \mathrm{~mm}$ in width, $3.0 \mathrm{~mm}$ in thickness, and $18.0 \mathrm{~mm}$ in gage length were produced for tensile tests and creep tests under atmospheric conditions. As shown in Fig. 1, we defined the built plane as the $Z$ plane, the vertical plane (i.e., the cut plane) as the $X$ plane, and the other plane as the $Y$ plane. The PF specimen was a rod with a diameter

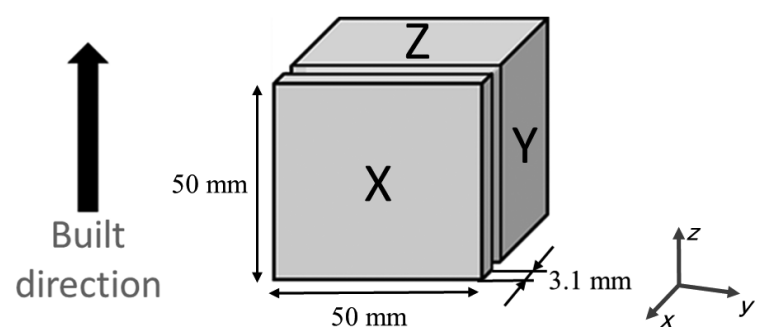

Fig. 1 Schematic illustration of the cutting of AM specimens for microstructural observation. 
Table 1 Chemical compositions of the powder and the PF material.

\begin{tabular}{ccccccccccccc}
\hline (mass\%) & $\mathrm{C}$ & $\mathrm{Si}$ & $\mathrm{Mn}$ & $\mathrm{P}$ & $\mathrm{S}$ & $\mathrm{Cu}$ & $\mathrm{Ni}$ & $\mathrm{Cr}$ & $\mathrm{Mo}$ & & & \\
\hline SUS316L powder & 0.024 & 0.48 & 1.22 & $<0.005$ & 0.005 & 0.01 & 12.08 & 16.92 & 2.40 & bal. \\
\hline PF SUS316L & 0.006 & 0.22 & 1.70 & 0.037 & 0.014 & - & 12.45 & 16.60 & 2.21 & bal. \\
\hline
\end{tabular}

of $20 \mathrm{~mm}$. After the hot working process, the PF rod underwent solution heat treatment (SHT) at $1080^{\circ} \mathrm{C}$ and water quenching (WQ). The PF tensile and creep specimens were fabricated by cutting along their loading axes, which ran in their longer direction. The microstructure of the PF specimens was observed on the cross-sectional plane of the rod. As the PF specimens underwent the SHT, we prepared the SHT specimens in addition to the as-built AM specimens. The AM specimens underwent the SHT at $1080^{\circ} \mathrm{C}$ for $1 \mathrm{~h}$ in an Ar atmosphere, and WQ. The tensile tests in this study were performed at $24^{\circ} \mathrm{C}$ and $600^{\circ} \mathrm{C}$. The creep tests were conducted at $600^{\circ} \mathrm{C}$ with stress levels of $235 \mathrm{MPa}$ and $260 \mathrm{MPa}$.

An optical microscope (OM) (Olympus BX60M), a scanning electron microscope (Hitachi S-3700N), and the electron back scatter diffraction (EBSD) method were used for structure observation, and a transmission electron microscope (TEM) (JEOL JEM-3200FS) was used for dislocation observation. For the observation of the MPBs, the as-built specimens were mounted, polished and electrolytically etched in diluted $\mathrm{H}_{3} \mathrm{PO}_{4}$ solution $\left(\mathrm{H}_{3} \mathrm{PO}_{4}: \mathrm{H}_{2} \mathrm{O}=7: 3\right)$ at $16^{\circ} \mathrm{C}, 4 \mathrm{~V}, 2.8 \mathrm{~A}$ for $70 \mathrm{~s}$. For EBSD analysis, the specimens were subjected to mechanical polishing with polishing paper to \#4000 and subjected to mechanical polishing with a diamond grindstone to $3 \mu \mathrm{m}$. Subsequently the specimens were mechanochemically polished with colloidal silica to $0.04 \mu \mathrm{m}$. Foil specimens for TEM observation were prepared by twin jet electropolishing in diluted $\mathrm{HClO}_{4}$ solution $\left(\mathrm{HClO}_{4}: \mathrm{C}_{2} \mathrm{H}_{5} \mathrm{OH}=9: 1\right)$

\section{Results}

The chessboard-like scanning pattern of the AM material is shown in a top view in Fig. 2. The area between the adjacent patterns was $7 \mathrm{~mm}^{2}$. As shown in Fig. 3, the laser scanning lines took the form of an acute angle with each other; thereby, we found that the laser scanning pattern rotated with an acute angle on each layer. Figure 4 shows the inverse pole figure (IPF) maps on the $X$ plane, the $Y$ plane, and the $Z$ plane in the AM as-built specimen. Figure 5 shows the IPF map of the PF (SHT) specimen. In this study, we defined the grain boundaries in these IPF maps to be over $10^{\circ}$ of misorientation. As shown in Fig. 4, the mixed grain structure, columnar grains, and fine grains were observed on the $X$ plane in the AM as-built specimen. On the other hand, columnar and coarse grains were observed on the $Y$ plane in the $\mathrm{AM}$ as-built specimen. On the $Z$ plane in the $\mathrm{AM}$ as-built specimen, the grains were oriented from the bottom left to the upper right, which corresponds to the laser scanning direction. As shown in three direction maps of Fig. 4 vertically long stone-monument-like grains were piled in a line. The equiaxed grain structure in the PF (SHT) specimen was observed (Fig. 5).

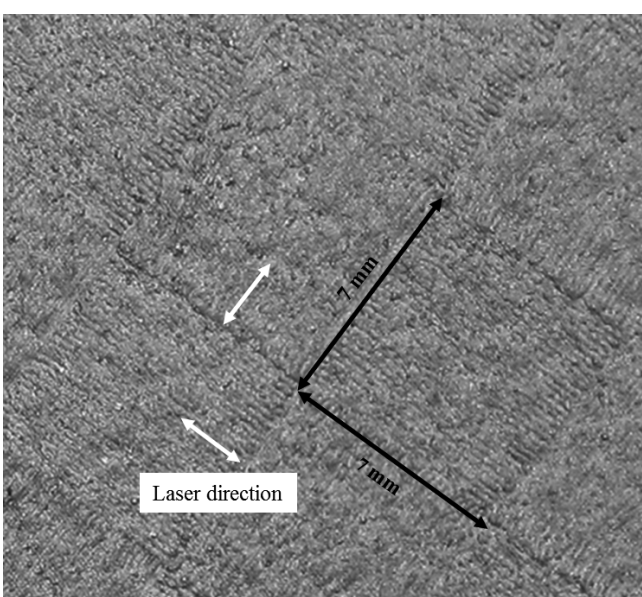

Fig. 2 Laser scanning trace on the top plane.

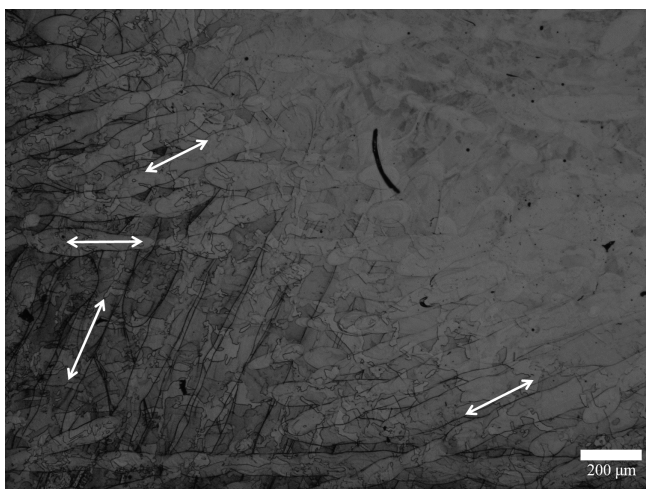

Fig. 3 Laser scanning trace on $Z$ plane of the as-built specimen.

Figures 6 and 7 show the stress-strain curves at $24^{\circ} \mathrm{C}$ and $600^{\circ} \mathrm{C}$, respectively. Table 2 summarizes the mechanical properties. In terms of strength anisotropy, the ultimate tensile strength (UTS) of the AM 90-deg specimens was higher than that of the AM 0-deg specimens at $24^{\circ} \mathrm{C}$ and $600^{\circ} \mathrm{C}$. In comparison to the PF (SHT) specimen, the UTS of the AM 90-deg as-built specimen was higher, but the UTS of the AM (SHT) 90-deg specimen was comparable to the UTS of the PF (SHT) specimen (Table 2). For the AM 90-deg specimens in the $600^{\circ} \mathrm{C}$ tensile test, regardless of the existence of the SHT, the UTS levels were approximately equal; however, for the AM 0-deg specimens, the UTS of the SHT specimen decreased $11 \%$ compared to that of the as-built specimen. In terms of ductility, the PF (SHT) specimens showed ductility that was twice as large as the AM 0-deg asbuilt specimens at $24^{\circ} \mathrm{C}$ and $600^{\circ} \mathrm{C}$. It was found that the built direction affects ductility for the AM material; the ductility of the AM (SHT) 90-deg specimen was lower than that of the AM (SHT) 0-deg specimen (Fig. 7(b)), although in other conditions regardless of the existence of the SHT, the 


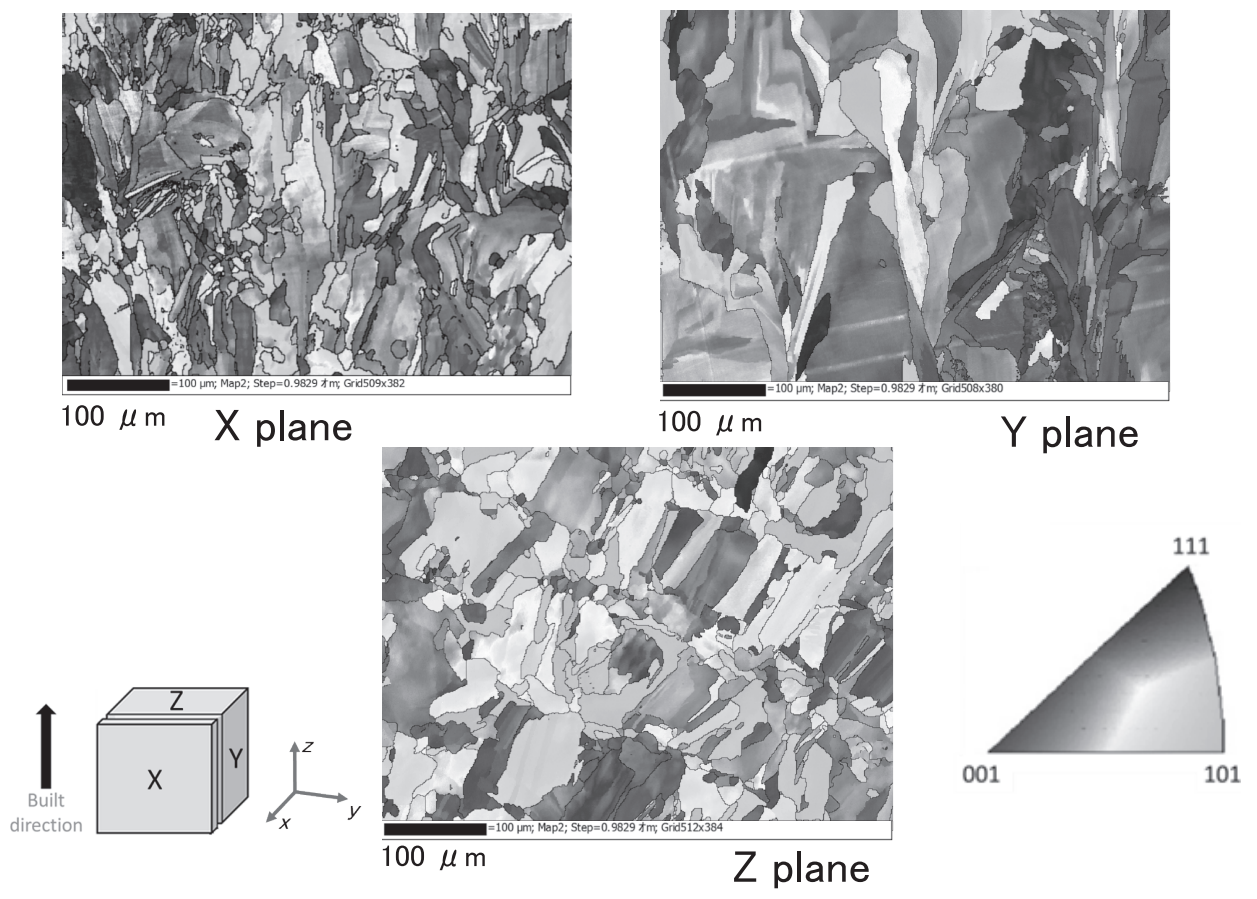

Fig. 4 IPF maps of the as-built specimen.
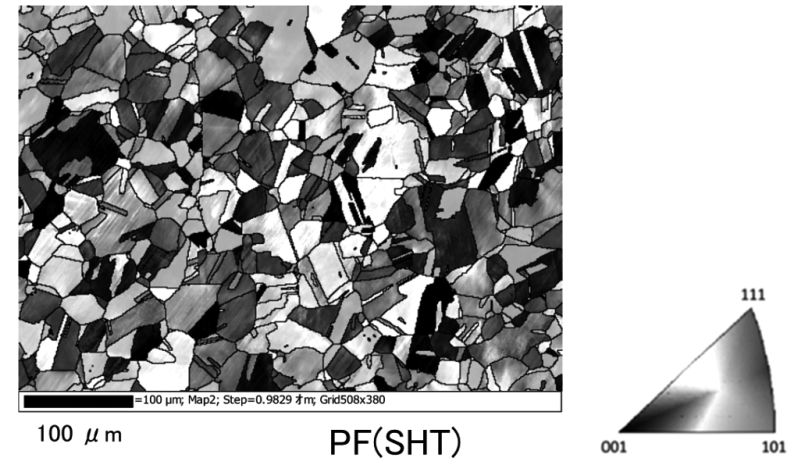

Fig. 5 IPF map of the PF (SHT) specimen.

AM 90-deg specimens demonstrated higher UTS and ductility than the AM 0-deg specimens.

Figure 8 shows the creep curves at $600^{\circ} \mathrm{C}$. In this study, the creep curve of the PF specimen is drawn from the data in the literature ${ }^{6)}$. When the creep test was conducted with a stress of $235 \mathrm{MPa}$, the creep strain of the AM 0-deg as-built specimen remained very low for $500 \mathrm{~h}$. On another front, the comparative PF specimen $^{6}$ ) fractured at $45.12 \mathrm{~h}$ with $50.62 \%$ in creep strain. When the creep testing was conducted with a stress of $260 \mathrm{MPa}$, the AM 0-deg as-built specimen fractured at $610 \mathrm{~h}$ with $12.39 \%$ in creep strain, and the AM 90-deg asbuilt specimen fractured at $692 \mathrm{~h}$ with $10.20 \%$ in creep strain. Compared to the AM 0-deg as-built specimen, the creep life of the AM 90-deg as-built specimen was slightly longer.

Figure 9 shows the TEM images of the AM as-built, the AM (SHT), and the PF (SHT) specimens. Many dislocation cell structures were observed in the AM as-built specimen (Fig. 9(a)); the dislocation density of the AM as-built specimen was $1.5 \times 10^{10} \mathrm{~cm} / \mathrm{cm}^{3}$. In the AM (SHT) specimen,
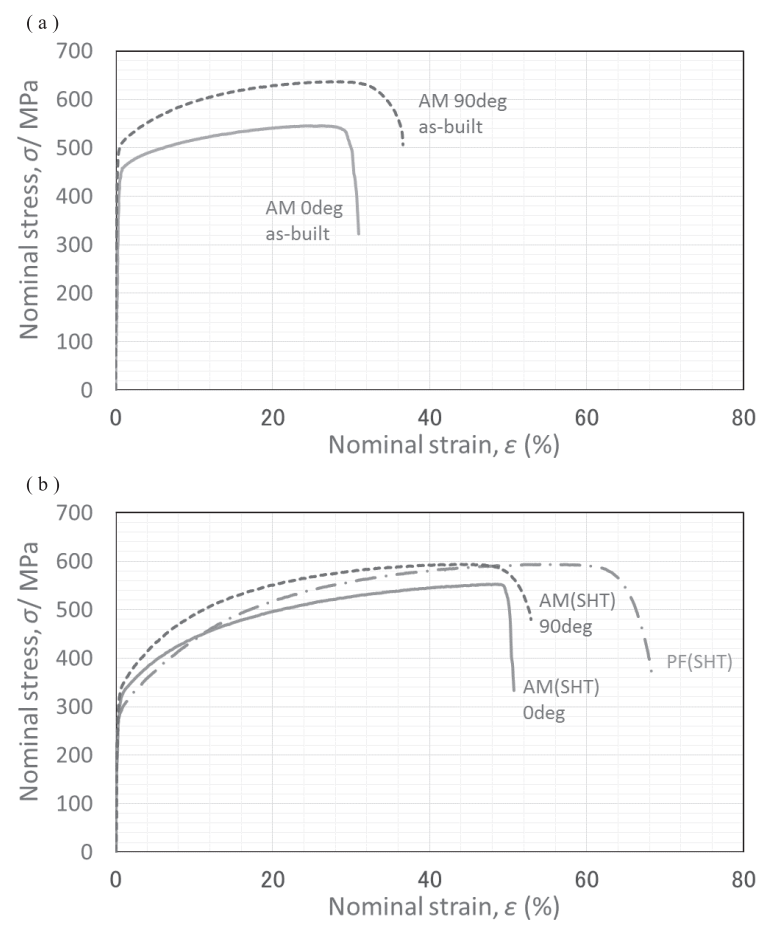

Fig. 6 Stress-strain curves at $24^{\circ} \mathrm{C}$. (a) As-built specimens, (b) SHT specimens.

the dislocation cell structures were extinct due to the recovery (Fig. 9(b)); the dislocation density of the AM (SHT) specimen was $9.7 \times 10^{9} \mathrm{~cm} / \mathrm{cm}^{3}$. The dislocation density of the PF (SHT) specimen was $3.5 \times 10^{9} \mathrm{~cm} / \mathrm{cm}^{3}$ and was lower than that of the AM as-built specimen (Fig. 9(c)). 

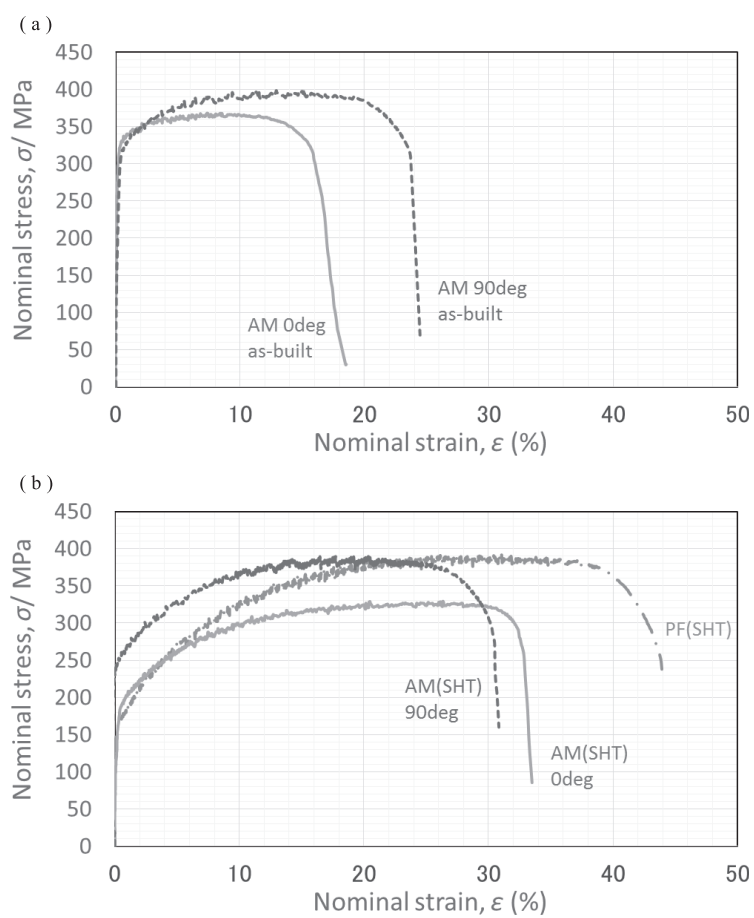

Fig. 7 Stress-strain curves at $600^{\circ} \mathrm{C}$. (a) As-built specimens, (b) SHT specimens.

Table 2 Mechanical properties of the tensile specimens.

\begin{tabular}{|c|c|c|c|c|}
\hline & & $\begin{array}{c}\text { Proof stress, } \\
0.2 \% \text { elastic offset, } \\
\mathrm{MPa}\end{array}$ & $\begin{array}{l}\text { UTS, } \\
\mathrm{MPa}\end{array}$ & $\begin{array}{c}\text { Total elongation, } \\
\%\end{array}$ \\
\hline \multirow{4}{*}{$24^{\circ} \mathrm{C}$} & AM $0 \mathrm{deg}$ & 439 & 546 & 31.0 \\
\hline & AM 90 deg & 482 & 636 & 36.6 \\
\hline & AM (SHT) $90 \mathrm{deg}$ & 322 & 593 & 52.9 \\
\hline & $\mathrm{PF}(\mathrm{SHT})$ & 272 & 593 & 68.4 \\
\hline \multirow{4}{*}{$600^{\circ} \mathrm{C}$} & AM 0 deg & 323 & 368 & 18.5 \\
\hline & AM 90 deg & 296 & 400 & 24.5 \\
\hline & AM (SHT) $0 \mathrm{deg}$ & 188 & 329 & 33.5 \\
\hline & $\mathrm{PF}(\mathrm{SHT})$ & 165 & 391 & 43.9 \\
\hline
\end{tabular}

\section{Discussion}

The tensile ductility at an elevated temperature of $\mathrm{Ni}$ based superalloy IN718 fabricated by the AM process which was extremely low $^{4}$ ) because the dendrites grew along the built direction and formed a columnar grain structure with a consequent failure arising between the dendrites ${ }^{7}$. In contrast, the ductility of the AM 90-deg specimens was higher than that of the AM 0-deg specimens. In cast SUS316L stainless steel, micro-segregation arises while solidification occurs and consequently a dendritic structure is formed ${ }^{8)}$. However, as the cooling rate of the AM material, $10^{6-7} \mathrm{~K} /$ $\mathrm{s}^{9)}$, is faster than that of the cast material, the specific dendritic structure observed in cast material was not observed in the AM material. Therefore, this was one of the reasons that the ductility of the AM 90-deg specimens was high and the cracking between dendrites did not occur. Moreover, as shown in Fig. 10, the defect due to the lack of fusion along the MPBs was observed. The area density of defects ob-
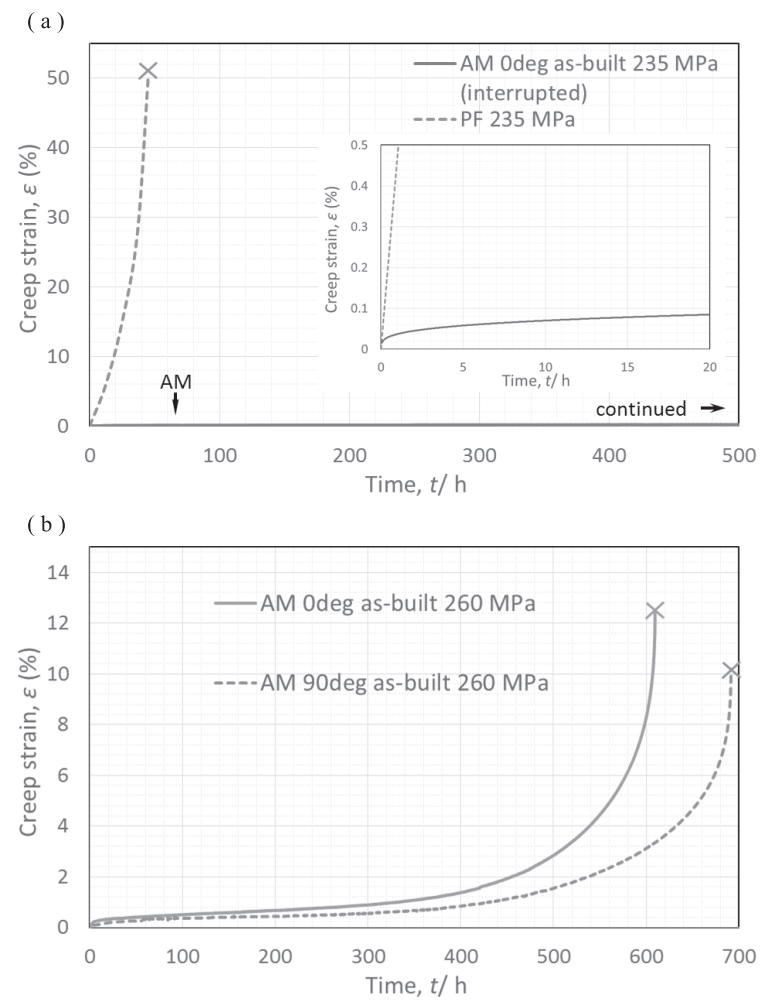

Fig. 8 Creep curves of the AM and PF specimens at $600^{\circ} \mathrm{C}$. (a) Comparison between the AM and the PF specimens, (b) Influence of the built direction on the creep curves.

served with $\mathrm{OM}$ was $1.19 \mathrm{~mm}^{-2}$. These defects extended parallel to the built plane. As for the AM 0-deg specimens, the tensile or creep load applied perpendicular to the defect was the primary reason that the strength and ductility decreased in that the defect was the originating point of the aperture crack. Another reason is that the cohesive strength of the MPBs is lower than that of the matrix ${ }^{10)}$. Moreover the MPBs did not have segregation. However, for the specimens that underwent SHT, the ductilities of the 0-deg specimen and the 90-deg specimen were approximately equal (Figs. 6(b) and 7(b)). Figure 11 shows the fracture regions ( $X$ plane) of the AM 0-deg as-built and AM (SHT) 0-deg specimens after the tensile test at $600^{\circ} \mathrm{C}$. Coarse voids were observed in the AM 0-deg as-built specimen; in contrast, shear lip was observed, and the coarse voids were not observed in the AM (SHT) 0-deg specimen because the defects along the MPBs which is one of the reasons the coarse voids were sintered due to diffusion by a solution temperature of $1080^{\circ} \mathrm{C}$. As defects due to the AM process were observed, process remediation such as hot isostatic press and defect detection technologies such as Micro $\mathrm{CT}^{5)}$ is needed ${ }^{11)}$.

As shown in Fig. 9, the dislocation cell structures were observed in the AM as-built structure, but the specimen that underwent SHT did not have the dislocation cell structures. The dislocation density of the PF (SHT) specimen was lower than that of the other specimens (Fig. 9(c)). For the reason noted below, the UTS and the creep strength of the AM asbuilt specimens were higher than those of the PF (SHT) specimens; at first the average grain diameter of the AM asbuilt and the PF (SHT) specimen were $10 \mu \mathrm{m}$ and $13 \mu \mathrm{m}$ respectively, the difference of grain diameter was small so we 

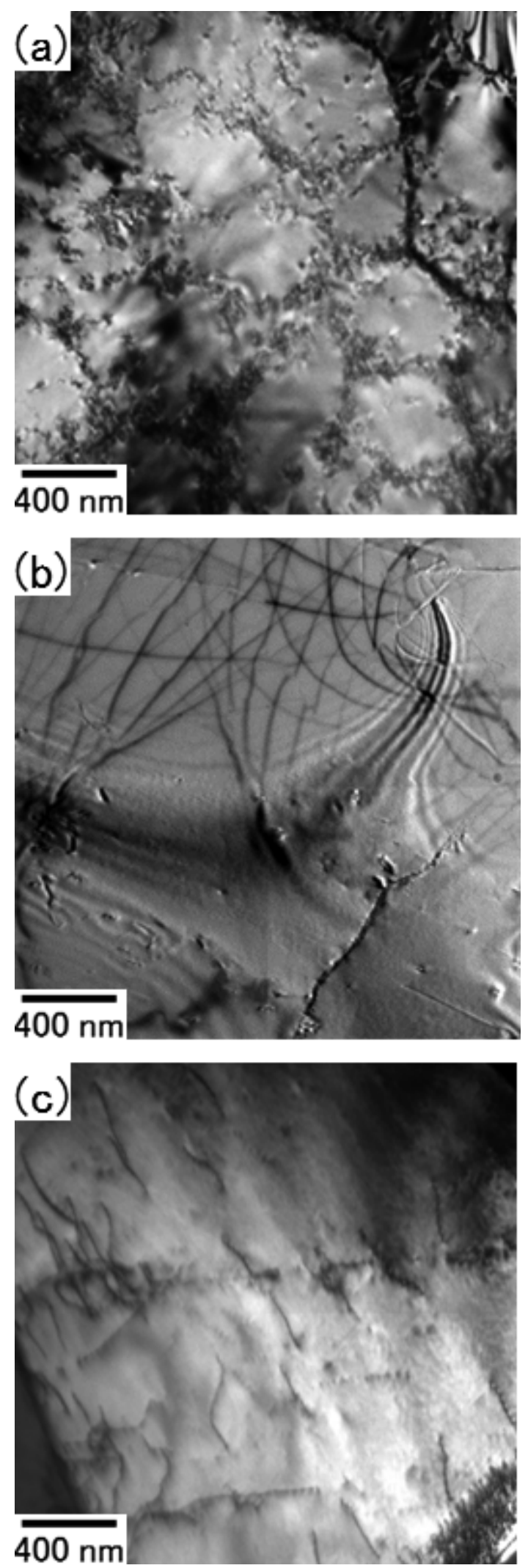

Fig. 9 TEM microstructure of the (a) AM as-built, (b) AM (SHT), and (c) PF (SHT) specimen.

can focus on dislocation. The AM process, which has a great number of heating-cooling cycles, introduced dislocation cell structures which have a high dislocation density. As for the AM (SHT) specimen, the dislocation cell structures in

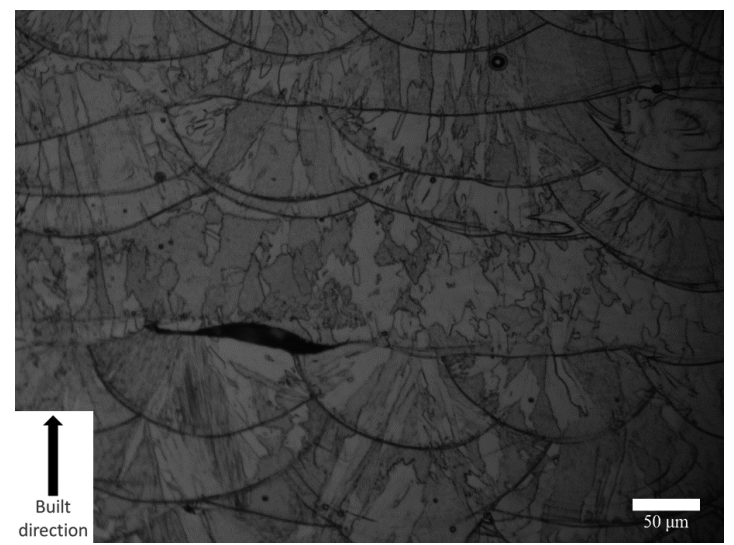

Fig. 10 OM image of the defect due to lack of fusion in the as-built specimen.
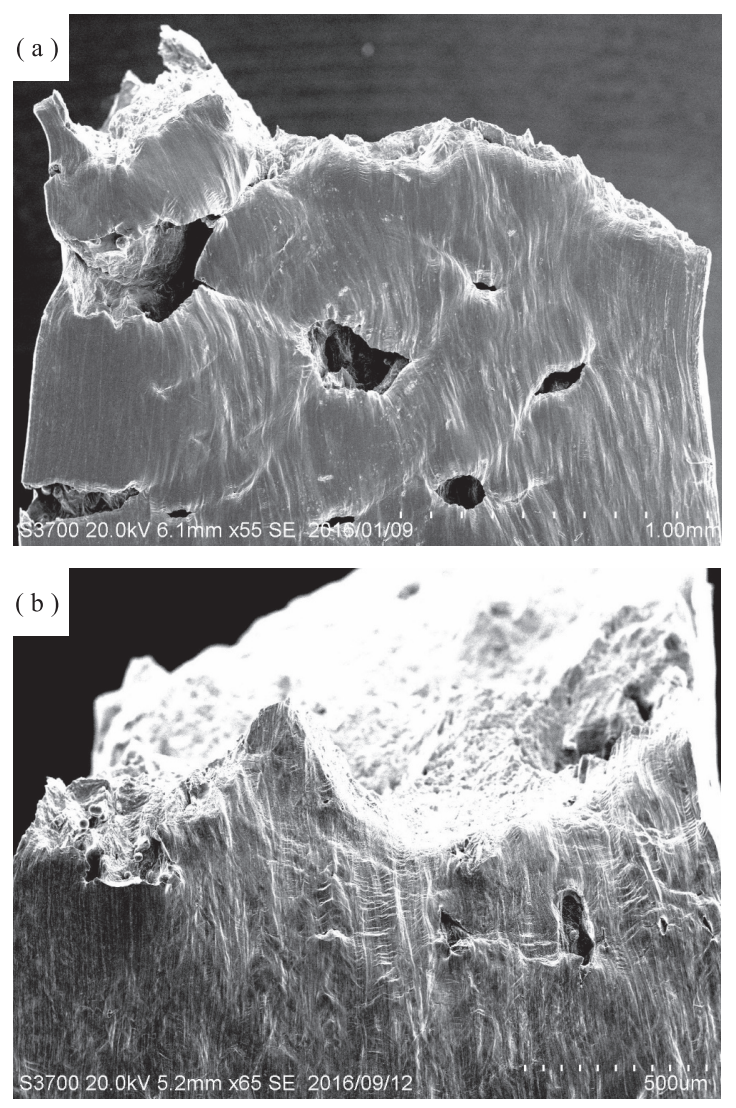

Fig. 11 Side view near the fracture surface of (a) AM 0-deg and (b) AM (SHT) 0-deg specimens tested at $600^{\circ} \mathrm{C}$

the AM as-built specimen disappeared as a result of the SHT process, and the dislocation density decreased, which consequently made the strength of the AM (SHT) specimen approximately equal to that of the PF (SHT) specimen. However, the AM material includes many defects; thereby its ductility is lower than that of the PF material under any heat treatment conditions.

\section{Conclusion}

(1) As defects due to the lack of fusion along the MPBs which do not have segregation exist, the ductility of the AM 
material was lower than that of the PF material. Moreover, the defects extended parallel to the built plane; therefore, the strength and ductility of the AM 0-deg specimens is lower than that of the AM 90-deg specimens.

(2) The UTS and creep strength of the AM as-built specimens are higher than those of the PF (SHT) specimens because of the presence of dislocation cell structures which have high dislocation density.

(3) For the specimens that underwent SHT, the ductilities of the 0-deg specimen and the 90-deg specimen were approximately equal because the defects along the MPBs which is one of the reasons for the coarse voids introduced during tensile deformation were sintered due to diffusion by solution temperature $1080^{\circ} \mathrm{C}$.

\section{Acknowledgments}

The authors would like to thank Dr. An-Chou Yeh of National Tsing Hua University, who cooperated on our study.

\section{REFERENCES}

1) K. Kakehi: Material Stage, Technical Information Institute 15 (2015) 45-52.

2) B. Vrancken, L. Thijs, J. Kruth and J.V. Humbeeck: J. Alloy. Compd. 541 (2012) 177-185.

3) S.H. Sun, Y. Koizumi, S. Kurosu, Y.P. Li, H. Matsumoto and A. Chiba: Acta Mater. 64 (2014) 154-168.

4) Y. Kuo and K. Kakehi: Proc. International Gas Turbine Congress 2015 (Gas Turbine Society of Japan) pp. 1031-1034.

5) L.N. Carter, C. Martin, P.J. Withers and M.M. Attallah: J. Alloy. Compd. 615 (2014) 338-347.

6) K. Kakehi: Master Thesis of Nagoya University, (1985).

7) K. Kakehi: Mechanical Engineering, Nikkan Kogyo Shimbun 64 (2016) 76-82.

8) M. Sugiyama, T. Umeda and J. Matsuyama: Tetsu-to-Hagané 60 (1974) 1094-1112.

9) Q. Jia and D. Gu: Opt. Laser Technol. 62 (2014) 161-171.

10) W. Shifeng, L. Shuai, W. Qingsong, C. Yan, Z. Sheng and S. Yusheng: J. Mater. Process. Technol. 214 (2014) 2660-2667.

11) M. Seifi, A. Salem, J. Beuth, O. Harrysson and J.J. Lewandowski: JOM 68 (2016) 747-764. 